Revista de la red interuniversitaria de estudios sobre las

literaturas rioplatenses contemporáneas en Francia

$9 \mid 2013$

Homenaje a Ana María Barrenechea

\title{
Cuento folklórico y narrativa oral : versiones, variantes y estudios de génesis
}

\section{María Inés Palleiro}

\section{OpenEdition}

\section{Journals}

Edición electrónica

URL: http://journals.openedition.org/lirico/1120

DOI: 10.4000/lirico.1120

ISSN: 2262-8339

Editor

Réseau interuniversitaire d'étude des littératures contemporaines du Río de la Plata

\section{Referencia electrónica}

María Inés Palleiro, "Cuento folklórico y narrativa oral : versiones, variantes y estudios de génesis »,

Cuadernos LIRICO [En línea], 9 | 2013, Puesto en línea el 01 septiembre 2013, consultado el 19 abril 2019. URL : http://journals.openedition.org/lirico/1120 ; DOI : 10.4000/lirico.1120

Este documento fue generado automáticamente el 19 abril 2019.

\section{cc)}

Cuadernos LIRICO está distribuido bajo una Licencia Creative Commons Atribución-NoComercialSinDerivar 4.0 Internacional. 


\title{
Cuento folklórico y narrativa oral : versiones, variantes y estudios de génesis
}

\author{
María Inés Palleiro
}

\begin{abstract}
Para progresar, la genética debe liberarse de los estudios de un corpus único y de puntos de vista

especializados. Será conveniente traspasar las fronteras. Los ejemplos podrán ser tomados de...los hipertextos electrónicos y de...sistemas semióticos heterogéneos. (Daniel Ferrer 1999 : 49. Mi
\end{abstract} traducción)

1 Presento aquí una aproximación a la narrativa oral desde una perspectiva genética, que desarrollé gracias al entusiasmo de Anita Barrenechea por los intereses de los que fuimos sus doctorandos. En mi Tesis Doctoral, analicé las variantes contextuales en un corpus de narrativa folklórica argentina. En una etapa posterior, vinculé las variantes del relato folklórico con las variantes textuales de los estudios genéticos. Esta teoría conjuga los aportes de la genética textual con los de la teoría informática del hipertexto (Palleiro 2004). Ofrezco en este trabajo un aspecto de tal propuesta, relacionado con mis investigaciones actuales.

\section{Aportes de la genética textual a los estudios sobre oralidad : versiones y variantes}

2 En su artículo "Qu' est ce que c'est la critique genétique », Grésillon (1994:7-31) caracteriza la perspectiva genética como "una mirada nueva» que privilegia «la génesis sobre la estructura ». Esta mirada propone reconstruir la génesis del texto a partir del estudio de variantes de manuscritos literarios. 
3 La aproximación a la genética textual desde la oralidad resulta en cierto modo paradójica. En lugar de subrayar la condición dinámica de un texto fijado en la escritura, los registros de narrativa oral intentan fijar relatos originados en el coloquio sin borrar las huellas de su génesis, en una tensión entre oralidad y escritura.

4 Así como la crítica genética estudia variantes de manuscritos, las variantes son también el eje de la oralidad folklórica. Ya Menéndez Pidal, en sus trabajos sobre el romancero hispánico, llamó la atención sobre la vida en variantes de la tradición oral. Chertudi (1978) afirma asimismo que el cuento folklórico «vive en variantes » en la oralidad, y define la versión como « cada realización de un cuento ».

5 Las regularidades temáticas del relato folklórico fueron estudiadas por la escuela finesa, representada por Aarne y Thompson, autores de los Índices de Tipos y Motivos del relato folklórico. ${ }^{1}$ El motivo es la unidad temática mínima de un cuento o relato, y la combinación relativamente estable de motivos configura un tipo. De este modo, motivos tales como la " pérdida del zapato » pueden recombinarse para dar lugar a tipos comunes a las más variadas latitudes y períodos históricos, como el de «Cenicienta». Tales regularidades están acompañadas por invariantes compositivas y estilísticas. El estudio de regularidades compositivas del relato folklórico fue iniciado por Propp, quien en su Morfología del cuento identificó unidades mínimas del nivel formal llamadas «funciones ", codificadas en un inventario cerrado de treinta y una. Desde una perspectiva estructural, Barthes asoció las unidades mínimas del relato con las « acciones » o " puntos de riesgo ». Greimas, por su parte, propuso un modelo actancial que reduce la estructura narrativa a las instancias de "ruptura del orden », "pruebas » y "restauración del orden», y clasificó los « actantes », encargados de realizar las acciones del relato, en seis categorías. ${ }^{2}$ Olrik codificó las regularidades estilísticas bajo la forma de «leyes del estilo folklórico » (Olrik 1992), entre las que se cuentan la del tres, la de la antítesis y la de repetición de situaciones paralelas.

6 Desde una perspectiva genética, Lebrave $(1990: 156)$ caracterizó las correcciones y variantes de manuscritos como operaciones materiales del acto de escritura, que reflejan su condición de texto en proceso. Propuso, como método para reconocer las variantes, un "desciframiento " basado en la confrontación de distintos estados de escritura, que permite distinguir adiciones, supresiones, desplazamientos y sustituciones de elementos. En mi propuesta, reformulo estos conceptos para la narración folklórica, alrededor de la noción de «matriz genética ».

7 Para los geneticistas, las correcciones modifican un texto ya fijado y las variantes introducen alternativas surgidas de la reflexión del autor sobre su propio discurso escrito. En mi aproximación a la narrativa oral, relaciono las correcciones con modificaciones textuales en el dominio del decir, y las variantes con transformaciones contextuales de las matrices en el dominio de lo ya dicho. Defino las matrices como combinaciones temáticas, compositivas y estilísticas comunes a distintos relatos, identificadas mediante la comparación intertextual. El relato folklórico se ajusta entonces por patrones de tema, composición y estilo constitutivos de las matrices. El concepto de matriz agrega a las regularidades temáticas de los tipos y motivos estudiados por el método históricocomparativo, que confronta versiones de distintos tiempos y lugares, elementos de composición y estilo subrayados por el formalismo ruso, el estructuralismo y la estilística.

8 Las matrices sirven como pretextos de itinerarios narrativos múltiples, cuyo contenido semántico se relaciona con identidades colectivas. Las correcciones y variantes 
introducen cambios en las matrices estabilizadas en el curso de la transmisión oral y de eventuales fijaciones escriturarias (Palleiro 2004). En sus estudios sobre memoria colectiva, Assman (1997) se refiere a las conexiones lábiles de la memoria. Los narradores archivan las matrices en su memoria, que favorece la combinación libre de unidades en relatos diferentes. Mi aproximación al relato folklórico busca desentrañar los mecanismos de transformación de estas matrices en situaciones comunicativas concretas.

\section{El relato folklórico: deconstrucción hipertextual y texto infinito}

9 El relato folklórico, como texto dinámico, tiene una potencialidad deconstructiva similar a la de un hipertexto virtual. Desde la teoría informática, Nelson define el hipertexto como un "texto que se bifurca», compuesto por "una serie de bloques textuales conectados entre sí por nexos que forman diferentes itinerarios para el usuario » (Nelson 1992: 2-3. La traducción es mía). Con este enfoque, el relato folklórico puede ser considerado como conjunto de bloques textuales constituido por unidades mínimas independientes y fragmentarias, conectadas mediante nexos flexibles. Tal mecanismo da como resultado una estructura de recorridos múltiples, a partir de transformaciones de una matriz pretextual que activa un mecanismo generador de correcciones y variantes similar al hipertexto de Nelson.

Este diseño tiene como base teórica el deconstruccionismo. Cowes (1996:255-269) establece una línea de continuidad entre el deconstruccionismo de Derrida y la estilística de Amado Alonso, a la que vincula con el formalismo ruso. Con agudeza crítica, se refiere a su propuesta de « desenfocar » o « desmoldar » las palabras, para observar que Amado Alonso "podría haber usado en su lugar el verbo 'deconstruir'«. En Marges de la Philosophie (1985), Derrida da cuenta de la importancia de los detalles marginales para la reflexión filosófica, que puede conectarse con la relevancia asignada a los detalles en la obra folklórica por el formalista Mukarovsky (1977). Este considera tales detalles en apariencia irrelevantes como elementos capaces de resignificar un mensaje. Estos planteos coinciden con el enfoque de Le Goff (1984: 81-98), quien advierte la posibilidad de acceder a la mentalidad de un grupo a través del estudio de documentos marginales, reveladores de «la conjunción de lo individual con lo colectivo». Mi propuesta tiene como fundamento la consideración de los detalles como unidades semánticas de la narración folklórica, que operan como nudos de descentramiento del relato. Al convertirse en ejes de su articulación compositiva, tales detalles favorecen la desagregación de los componentes temáticos y estilísticos de la matriz en un juego de combinaciones múltiples.

La dinámica del texto fue también señalada por Amado Alonso en su ensayo sobre la forma interior del lenguaje en Humboldt. Barrenechea (1983) retoma esta concepción dinámica que tiene Humboldt del lenguaje como energeia o proceso, y la considera un fundamento de los estudios genéticos. En esta línea marcada por Cowes y Barrenechea, inscribo mi propuesta de aproximación al relato folklórico, que tiene en cuenta los aportes formalistas de Propp y Mukarovsky, y los estudios estructurales de Barthes sobre estructura narrativa y articulación retórica (Barthes 1974). Los patrones de tema, composición y estilo tienen como base las categorías propuestas por Bajtín (1982) para delimitar los géneros discursivos. Tales patrones constituyen un inventario abierto, que 
cada nuevo narrador transforma, por medio de correcciones y variantes. Los agregados, eliminaciones, reemplazos o cambios de posición de núcleos narrativos, que dan lugar a tales correcciones variantes, guardan semejanza con las adiciones, supresiones, sustituciones y desplazamientos identificados por los manuscritólogos en textos escritos. Identifico en primer lugar las regularidades temáticas, compositivas y estilísticas que conforman una matriz, y estudio luego sus variantes y bifurcaciones múltiples. Tales bifurcaciones reproducen el dinamismo de la memoria y revelan la inexistencia de un texto originario.

\section{De « Juan Catorce » a « El Golem » : itinerarios de dispersión de una matriz narrativa}

Para ejemplificar esta propuesta, analizaré algunas manifestaciones de la matriz « El gigante forzudo ", que identifiqué mediante la confrontación intertextual de versiones. ${ }^{3}$ En esta oportunidad, tomo como punto de partida la versión de la narradora riojana Andrea Cerda, recogida en una investigación de campo. Examino luego recorridos alternativos en una versión escrita de la leyenda del Golem ambientada en Buenos Aires, y me ocupo por último de su recreación literaria en la obra de Borges, cuya « expresión de la irrealidad » fue magistralmente estudiada por Anita (Barrenechea 1984). Este examen apunta a subrayar la dispersión de itinerarios del relato folklórico, y la dinámica entre tradición oral y cultura letrada.

\section{La matriz folklórica en sus distintos soportes}

La matriz de «El gigante forzudo » tiene rasgos temáticos comunes con el tipo narrativo ATU 650A, "Strong John », que cuenta entre sus fijaciones textuales el episodio bíblico de Sansón y los filisteos. ${ }^{4}$ De este tipo universal, la versión riojana desarrolla el tópico de la fuerza y apetito descomunales del protagonista, que sale en busca de aventuras y cumple pruebas reveladoras de sus habilidades extraordinarias. El recurso retórico dominante es la hipérbole, desplegada en la combinación episódica. De esta matriz, la leyenda urbana toma como eje la fuerza del gigante, capaz de proteger a una entera comunidad; y el poema de Borges, su monstruosidad y curioso origen.

\section{« Juan Catorce » de Andrea Cerda : una versión oral riojana}

El cuento "Juan Catorce", narrado por Andrea Cerda, forma parte del repertorio transmitido de boca de su abuelo, el célebre « mentiroso » don Nazario Cerda. Recogí este relato en la localidad de Chilecito de la provincia argentina de La Rioja en agosto del año 1987, cuando la narradora tenía once años y mantenía un contacto fluido con su abuelo.

\section{«Juan Catorce »}

Bueno, se trata de un chico que era el único hijo de la madre, ¿no?

Y le comía catorce vacas al día, y era muy fortachón, el chico.

Y una vez, ya no tenía más vacas, ovejas, ni nada, y se tuvo que ir de la casa ¿no ?

Y la madre le preparó una comida, y bueno, y se va. Llega a un palacio, y un rey le da trabajo.

Entonces, le dice el chico que bueno, pero con condición que le....estee...noo...que me dé catorce vacas por día [En este diálogo, la narradora adopta un tono de voz más agudo para reproducir la voz de Juan Catorce ; uno más grave, para la voz del 
rey, y otro aún más agudo, para la de su esposa]

-¡Bueno, vamos a ver !- dice el rey, y se va al dormitorio, y conversa con la esposa.

Y dice ella :-jNoo, él ya nos va a gastar todas las vacas, y todo; y nosotros nos vamos a fundir, así !- dice.

-¡Bueno, pero lo vamos a tratar de correr !- dice el rey.

Bueno, y al otro día, le dio trabajo. Entonces, dice :-¡Bueh, usté me va a ir p'ahí, pa'

'l cerro, y ahí, en la loma! Ahí va a ver una rama ¿no ? y esa rama es fundamental para arriar a las vacas de ahí. Y usté antes las tiene que llamar, a las vacas, pa' que vengan, y después va, y las va a arriar. [La narradora señala con su dedo índice derecho una dirección cercana que toma como eje el lugar de enunciación]

Y llega al cerro, y agarra la rama, y se va a llamar a las vacas.

Y entonces va a llamarlas, y dice que las llama y les grita :-¡Hijas, hijas! [En este discurso directo, la narradora utiliza un registro tonal agudo y aumenta la velocidad de emisión. Este registro contrasta con la entonación no marcada del narrador general, y el contraste provoca risas en el auditorio]

$\mathrm{Y}$ aparecían las vacas, aparecían todas.

¡¡Eeh, que tiene vacas, el patroncito!- que decía el Juan Catorce. Y que seguía llamando:- ¡Hijas, hijas !- Y que venían toodas las vacas. [En este nuevo discurso directo, la narradora adopta un tono agudo y enfático para reproducir el grito de llamada de las vacas, que suscita nuevas sonrisas en los oyentes]

Y en una de esas, ve como un refucilo : ¡¡Eh, mierda ! ¿Qué pasa? - [En este discurso directo, la narradora utiliza una entonación grave y casi susurrante, que genera risas en el auditorio. Dicho registro tonal se contrapone con la entonación aguda y enfática de la emisión siguiente]

-¡Hijas !- seguía llamando- ¡Hijas, hijas !

Y venían, las vacas.

Y después, de nuevo ve el refucilo :-¡Qué ! ¡Parece que está por llover !- que dice.

Bueno, y sigue llamando, y ya, ya viene más y más cerca, el refucilo.

Entonces, dice que el refucilo ése era un toro, el toro Astas de Oro, dice.

-¡Eeh, que tiene un torito mi patroncito !- que dice el Juan Catorce. [La narradora adopta un tono de voz más agudo y enfático para reproducir la exclamación de Juan Catorce]

Bueno, entonces dice que va y viene. $\mathrm{Y}$ dice que va $\mathrm{y}$ viene, el toro, $\mathrm{y}$ viene, $\mathrm{y}$ lo viene a encarar, y le pega una cachetada, el Juan Catorce, y lo mata, lo descoyota, al toro.

Y bueno, y después viene con el toro cargado, ahí, adonde estaba el rey.

Y dice que le dice :-¿Cómo anda, Juan? [En la emisión correspondiente al discurso directo del rey, la narradora emplea una entonación no marcada que se contrapone con el tono más grave y pausado de la emisión siguiente. Este mismo contrapunto tonal se reitera en los segmentos de diálogo del relato]

-¿Cómo anda, Juan? ¿Qué me le ha pasáu, Juan?

- ¡Mire, patroncito, acá venía un refucilo, y era un toro Astas de Oro, y le he pegado una cachetada, y se ha muerto! [En este segmento de discurso de Juan Catorce, la narradora adopta una mayor velocidad de emisión y un tono agudo, que contrasta con el registro grave y pausado adoptado para reproducir la voz del rey]

- ¡Bueno, no importa !- que dice el rey.

Bueno, y va, el rey, y le da catorce vacas. Y que Juan se come, nomás, las catorce vacas.

Bueno, y al otro día, lo mandan a un cerro.

Que había un río, atrás del cerro, y tenía que sacar todas las ramas del campo, y correr el cerro ; y después, cambiarlo de lugar al río, y regar los árboles ; y después, volver a poner la montaña ahí para que no pase más agua del otro lado.

Y todo eso, en un día, que lo tenía que hacer.

Bueno, y que dice el rey :-¡Qué ! ¡Este no lo va a hacer, y va a tardar muchos días dice- en romper el cerro, y todo !- dice el rey.

Bueno, y le ha dado un pico y una pala, el rey, a Juan. 
Y bueno, que se va, nomás, en el caballo, Juan.

Y dice que va ahí, como ser... dice que va, y agarra todo, dice [La narradora apunta con su dedo índice hacia un lugar cercano, y realiza el ademán de asir un bulto con sus brazos y manos] Con el pico, lo saca, al cerro, lo da vuelta, hace pasar todo el río, y riega así todos los árboles. Y saca también todas las ramas, con la pala ; las saca a todas las ramas, y todo.

Y después va, y lo saca toodo, y a las ramas que quedaban, las hizo un cerco.

Y después, quedaba todo el barro, así, en el campo [La narradora realiza el ademán de extender y mover ambas manos, para indicar la dispersión del barro]

Y después, va a llamarlo al patrón, y dice : -jYa lo hice todo !- que dice.

Y dice :-¿Cómo lo hizo ?- que dice el rey. [Durante el segmento de discurso directo anterior, la narradora acelera la velocidad de emisión y emplea un tono más agudo para la voz de Juan Catorce, que contrasta con la entonación grave usada para la voz del rey]

Y dice : - ¡Sií, ya lo hice todo!

Bueno, y va el patrón, y dice que conversa con la esposa : - ¡Eeh! ¡Nos va a fundir, esto!

Ya se iba comiendo el montón de vacas, el Juan Catorce.

- ¡Ya nos va a fundir !- que dice la esposa. [La narradora adopta un tono de voz ligeramente más agudo y enfático en el discurso directo de la esposa del rey]

Bueno, y al otro día... al otro día, el Juan Catorce va, y lo lleva al patroncito a ver, y le muestra el campo, y lo que había hecho.

Y dice : ¡¡Es increíble !- que dice el rey, y le dice :- ¿Y por dónde se entra? [La narradora utiliza una entonación más grave para la voz del rey]

Y había hecho una puerta, y todo. Y después, entra por la puerta, el rey, con el Juan Catorce, y estaba todo lleno de barro todo con el agua.

Bueno, y se vuelven, y ahí nomás el Juan se ha comido otra vez las catorce vacas.

Y que entonces, que le dice el rey a su esposa : ¡¡Y bueno! ¿Qué vamos a hacer ? ¡Le vamos a tener que dar la mano de nuestra hija!

Y dice que le dice el rey a Juan :-¡Mire, Juan! ¡Nosotros ya no tenemos más trabajo que le demos, y por eso, ahora le vamos a dar la mano de nuestra hija!

¡¡Cómo no, cómo no, cómo no!

- ¡Pero primero, tiene que ir a pasar por el callejón de los tigres!

-¡Bueno, bueno !- que dice Juan.

- ¡Bueno, acá lo van a matar, y ya nos vamos a quedar con la hija, nomás !- que le dice el rey a su esposa.

Y que la esposa le dice: -¡Menos mal; si no, nos vamos a fundir, y encima, nos vamos a quedar sin la hija! [La narradora utiliza una entonación más grave y enfática para la voz del rey ; una ligeramente más aguda, para la de la reina ; y otra aún más aguda y veloz, para la voz de Juan]

Y bueno, dice que va, Juan, y se va con el caballo, y dice que empiezan a venir los tigres.

Y dice Juan : - ¡Ve los gatos, mire los gatos !- dice. [La narradora apunta con su dedo índice hacia un objeto imaginario. Emplea además un tono agudo y aumenta la velocidad de emisión, generando risas en el auditorio]

Bueno, que agarraba a cachetadas, a todos los "gatos". Y después venía, y tenía que traer el caballo, ir caminando, y traer el caballo lleeno de gatos, dice.

Y llega, y le dice el patroncito : - ¿Cómo le va, Juan?

-¿Cómo le va, Juan? ¿Cómo anda, Juan? ¿Cómo anda, Juan? [En el diálogo precedente, la narradora adopta primeramente una entonación no marcada; y luego, un registro cada vez más grave, para cada una de las repeticiones]

- ¡Mire, acá, ahí me han agarrado en el callejón un montón de gatos, y los he tenido que matar !- que dice.

Bueno, y dice el rey ique esto no puede ser; que es muy fortachón, el Juan! [La narradora cambia el registro tonal hacia uno más grave, que realza el contrapunto polifónico de alternancia de las voces del narrador y del rey] 
Y dice : -¡Bueno, vamos a tener que darle la mano de nuestra hija !- dice el rey.

Bueno, van, y hacen una fiesta, toodo, y catorce vacas para Juan, nomás.

Y dice que va Juan, con la chica, nomás, y se casan, y todo, dice.

Y ahí han andado todos en farras, todos con la guitarra, y ahí ha andado también mi papá con mi abuelo, tocando la guitarra.

Este recorrido de la matriz tiene como eje el motivo folklórico de las tareas imposibles que el protagonista debe superar para obtener la mano de una princesa. ${ }^{5}$ Tales tareas, articuladas según la « ley del tres » del estilo folklórico (Olrik 1992), consisten en arriar vacas con una rama, enfrentarse con el toro Astas de Oro y pasar por el callejón de los tigres. Todas ellas se relacionan con el campo semántico de las faenas rurales, que incide en la doble designación del Destinador de la princesa (Greimas 1976) como « rey » y como "patrón» de una finca. Esta doble mención forma parte de los desdoblamientos referenciales propios del discurso ficcional. Reisz (1979) caracteriza los procedimientos de ficcionalización como duplicaciones de los componentes del hecho enunciativo : emisor, receptor y referente. Las duplicaciones del emisor pueden advertirse en las distintas voces incorporadas mediante verbos declarativos, en formas tales como "dice que », con un valor formulaico. Se trata de estrategias de «actuación mediacional » (Bauman 2000) que presentan el relato como reedición de discursos anteriores a cargo de un emisor colectivo, y que convierten a la narradora en eslabón de una cadena de discursos anteriores, mediados por el proceso de transmisión oral.

La narradora agrega referencias a las vacas, los cerros y otros elementos del paisaje rural riojano, que crean un efecto de realidad. Aspectos del tipo folklórico tales como la mención a « la dama de los bosques» son suprimidos y reemplazados por « el toro Astas de Oro » de la mitología local. Este personaje, que actúa como Antagonista (Greimas op.cit.), aparece asociado a la vez, en una identificación metafórica, con fenómenos naturales como el refucilo o relámpago, y con una deidad indígena ( ...el refucilo era...el toro Astas de Oro... $).{ }^{6}$ La mención de esta deidad zoomorfa resignifica las tareas imposibles como pasos rituales asociados con una creencia local. Es así como el paso del héroe por el «callejón de los tigres » adquiere el sentido de un rito iniciático. El discurso ritual entra así en el mundo fictivo del cuento y transforma la matriz, mediante correcciones y variantes, en mensaje identificador de un grupo. La mención del padre y del abuelo de la narradora "tocando la guitarra", en actitud característica de una celebración criolla, son agregados contextuales que sitúan al relato en una genealogía narrativa.

La elaboración estilística tiene como eje la antítesis entre maximización y minimización que acompaña a la hipérbole, unida al uso metafórico. La maximización aparece ya en el apelativo «Juan Catorce » que alude a la voracidad exagerada del protagonista, capaz de comer «catorce vacas al día». Tal fuerza y voracidad desmesuradas tienen como correlato la minimización de los opositores, designados mediante los diminutivos « torito " y « gatito ». Sobresale el estilo dialógico, acompañado de mímica y gestos que favorecen el despliegue teatral de la acción. Tal despliegue teatral intensifica la ilusión de realidad, y otorga al relato una textura polifónica que resignifica el discurso de su abuelo. Este personaje tiene el valor de símbolo de una tradición familiar que la narradora actualiza con un estilo propio, introduciendo variantes en la matriz general. 


\section{«El gigante del Once » : variantes de la matriz en una leyenda urbana} cláusulas explicativas con el agregado de testimonios de « vecinos » y otras citas. Estas se extienden desde la Biblia hasta la Kaballah y diversas tradiciones judías, entretejidas con documentos de archivos barriales, que anclan la matriz en el contexto de un grupo migrante en Buenos Aires. El relato es presentado como «mito» de un «personaje fabuloso ", asociado con la " historia de Balvanera », que aparece en " archivos » como « un documento fechado en 1930 ». Las citas se remontan al libro del Génesis, con su remisión a un tiempo mítico ab origine en el que « había gigantes en la Tierra », al libro de los Números y al « mito rabínico del Golem » de la tradición judaica. El texto intenta atraer la atención del lector mediante recursos como la hipérbole referida al tamaño del gigante, presente también en la versión riojana. Utiliza metáforas, asociadas con la condensación simbólica de tradiciones, y citas de autoridad como pruebas argumentativas de la verosimilitud del relato. El gigante condensa significaciones relacionadas con la cultura del grupo migrante y sus temores frente a un medio hostil.

El juego intertextual de citas sobre la existencia histórica del rabino remite a la cultura letrada, del mismo modo que el léxico cuidado, con términos como " humanoide », y la sintaxis con abundancia de cláusulas aclaratorias. El agregado de testimonios está en tensión con la ambigüedad de indicios sobre la existencia histórica del personaje. El narrador presenta una interpretación de tales testimonios sobre la « leyenda » rabínica del Golem, a la que asocia con una « historia » que « data del siglo XVI, cuando un rabino de Praga ... creó un hombre artificial » cuya vida " se debía al influjo de una inscripción mágica... ». La mención de Yehuda Ben Betzalel Löwe, rabino entre 1525 y 1609, constituye una variante aditiva, que remite a la versión referida por Scholem en la Enciclopedia Judaica. Según esta leyenda, un rabino descubre el nombre secreto de Dios y fabrica un muñeco al que nombra Golem. Esta versión, que tiene como eje la creación del Golem, especifica que « fueron creados...trece humanoides de arcilla ». Este es también un agregado con respecto a la versión oral, que suprime toda mención al origen del protagonista. La leyenda suprime la referencia a las tres tareas particulares del gigante, y las sustituye por la tarea general de proteger a la comunidad judía porteña. Menciona asimismo la existencia de versiones orales, en una reflexión metadiscursiva : 
...una versión dice que un rabino mezcló uno [de los muñecos] ...con los judíos que llegaron a Buenos Aires [y que] el escondite de este personaje [está en] un pasaje en forma de L llamado "Colombo", o "en el pasaje Victoria"...cuya única entrada está ubicada sobre Adolfo Alsina ...entre las misteriosas "medias estaciones del subte A : Pasco y Alberti” ... en donde el barrio de Balvanera se confunde con el de Congreso.

Todas estas especificaciones constituyen variantes, como la ubicación sustitutiva en dos lugares diferentes : el pasaje Colombo o las «medias estaciones del subte ». La referencia a las medias estaciones tiene connotaciones folklóricas que remiten a una dinámica metonímica de quiebre. Este quiebre simboliza la ruptura con lo cotidiano y el acceso a un ámbito misterioso, asociado con los medios espacios. En sus reflexiones sobre la literatura fantástica, Todorov (1982) se refiere a la fisura entre lo extraño que no traspasa los límites de lo real, y lo maravilloso, asociado directamente con lo ficticio. Esta fisura sitúa el relato en una zona intermedia entre ficción y realidad, propia de lo fantástico. El gigante del Once se ubica en este espacio fronterizo, vinculado a la vez con la tradición rabínica del Golem y con los relatos sobre gigantes de la tradición oral argentina. La fragmentación por mitades tiene como contrapartida el motivo folklórico del doble, cuya expresión simbólica es la creación de «humanoides de arcilla». Tal creación adquiere matices cosmogónicos referidos a la creación del hombre imitada por el rabino, y a la creación duplicante de un universo ficcional, aludido por Borges.

En comparación con el relato riojano, hay desplazamientos secuenciales como el del episodio central de las tareas del gigante, llevado aquí a una posición final que lo vincula con la protección del grupo migrante. A diferencia del cuento riojano, centrado en el desarrollo secuencial, el eje de interés de esta leyenda es construir una tradición urbana relacionada con el cambio de configuración étnica producido por la inmigración. En una cláusula aclaratoria, el narrador agrega una «explicación lógica " de esta "historia ", vinculada con la «corriente inmigratoria que habría favorecido el aumento de la talla promedio » de los habitantes de la ciudad. Este agregado se conecta con la «necesidad de protección que sintieron los inmigrantes al llegar a nuestro extraño territorio [en donde] la leyenda de un Golem guardián habría ayudado psicológicamente a los recién llegados ». El narrador reconoce la condición simbólica del gigante como guardián protector del grupo inmigratorio en una cláusula interpretativa, en la que el uso del condicional marca su distancia con respecto al enunciado. Este adquiere entonces el valor de afirmación modalizada que se vincula con el "nacimiento del mito", caracterizado por una ambigüedad en la que «siempre habrá un espacio para el cuestionamiento, para la sospecha, para el rumor... alimentos de la leyenda... ». La suspensión de la creencia es considerada en efecto por Dégh (1976) como rasgo distintivo del discurso legendario. Se trata de un discurso ficcional, en el que el mundo real da paso a un mundo posible regido por leyes propias. La leyenda, basada en la identificación metafórica del gigante con un grupo, se caracteriza por estas modalizaciones que sitúan el relato en la dimensión relativizante de la creencia, y reemplazan lo verdadero por lo verosímil. La narradora oral juega con el verosímil narrativo de un modo más directo, relacionado con la referencia a testigos oculares y a la voz polifónica del grupo. Tanto el cuento riojano como la leyenda contextualizan la matriz en un entorno local, para convertirla en vehículo de expresión de colectivos sociales diferentes. 


\section{Reescrituras literarias en la obra de Borges}

\section{irrealidad en el ámbito cotidiano, para introducir la oralidad en el discurso literario.} Dedica un poema a «El Golem » y otro a «La fundación mítica de Buenos Aires », en el que concibe una fundación imaginaria de la ciudad. Tal fundación responde a un programa poético que sostiene que fundar míticamente una ciudad consiste en enraizarla en su propia experiencia. Construye de este modo un itinerario alternativo de la fundación de Buenos Aires, en un mundo posible teñido por la subjetividad. ${ }^{7}$ El poema adquiere una dimensión narrativa, que alude a la fundación histórica de Buenos Aires en la que los expedicionarios españoles se enfrentaron con las culturas indígenas locales. $\mathrm{El}$ poeta traza un recorrido opcional de este suceso, concebible, compatible y accesible desde la experiencia histórica. El matiz subjetivo está marcado por el condicional, con un matiz de irrealidad ( «... Irían a los tumbos los barquitos »), en un contrapunto con la alusión a « lo cierto » (« ...Lo cierto es que mil hombres... arribaron... »). Tal contrapunto se vincula con la creencia, en una dinámica entre suposición y certeza que da pie para una referencia a seres míticos de la civilización europea (" ...supondremos que el río... era azulejo... poblado de sirenas... y de piedras imanes...»). A partir de una adversación, propone una fundación subjetiva de la ciudad localizada en su barrio ("...Pero...fue una manzana entera y en mi barrio: en Palermo...»). Ancla de este modo la fundación imaginaria en ciertos símbolos de la cultura local: el truco, el tango, el "almacén rosado " y el compadrito del arrabal porteño. Todos estos elementos resultan compatibles en "... un pasado ilusorio... », concebible en la dimensión de un tiempo mítico "tan eterno como el agua y el aire ». La visión perspectivista de Borges presenta posibilidades múltiples de acceso al mundo poético a partir de un referente real, que resignifica la historia de la ciudad con símbolos sostenidos por creencias sociales, en un proceso de invención de tradiciones.

El universo de las tradiciones está presente también en el poema "El Golem», que reelabora la matriz de «El gigante forzudo » en una reflexión metacomunicativa sobre la creación poética. En este poema, el Golem es un «muñeco » creado por un rabino de Praga. Borges sustituye su rol de protector mencionado en la leyenda urbana por la referencia a su aspecto monstruoso (« ... Algo anormal y tosco hubo en el Golem... »). En un juego de espejos, presenta al rabino en su creación del muñeco mediante un acto de "alta hechicería » que intenta reflejar el acto divino de creación del hombre. En una adición con respecto a la matriz, cita a la tarea de Scholem de fijar por escrito la tradición oral judía (« ...El cabalista que ofició de numen /a la... criatura apodó Golem; / (estas verdades las refiere Scholem/ en un docto... volumen...»). Agrega variantes como el detalle del «gato » asustado ante la presencia del Golem, que da lugar a una reflexión metapoética. Tal reflexión está introducida mediante el recurso de corrección, que aclara entre paréntesis el sentido del texto ( ... (Ese gato no está en Scholem/ pero, a través del tiempo, lo adivino.) ...»). Propone un itinerario alternativo de la matriz, en un contrapunto intertextual con la obra de Scholem que introduce una nueva variante con respecto a la leyenda urbana. Mientras que en esta última el Golem era un protector de la comunidad, en Borges es un doble ficcional de la creación del hombre. La tradición recreada por Borges está ambientada en el illo tempore impreciso. Este pasado ambiguo está mencionado en la fórmula « ... hubo un día... » similar al « Había una vez » del cuento folklórico, que es una marca de oralidad en el poema. Hay una supresión de referencias a 
las aventuras del gigante, y una sustitución del contexto urbano de Buenos Aires por el de « la judería » de Praga. La matriz sirve como pretexto para una elaboración poética que entrelaza la tradición cabalística con una reflexión sobre el lenguaje vinculada con la cultura grecolatina y con la disputa medieval sobre el nominalismo. Las variantes de la oralidad se entrelazan en un juego intertextual de fuentes eruditas como el diálogo platónico Cratilo sobre el lenguaje. Tal entramado polifónico envuelve esta versión en la realidad conjetural de la creación poética.

La dinámica de itinerarios dispersivos de la oralidad folklórica es también un rasgo distintivo de la poética de Borges. Este propone a los lectores un juego perspectivista de aproximaciones diversas a un mismo referente, propio de una realidad conjetural en la que toda certeza está mediada por la creencia. Construye así un espacio laberíntico de mundos alternativos, en el que las versiones y variantes constituyen «senderos que se bifurcan» en un juego de opciones múltiples. Se trata de la «tentativa de un texto infinito » (Rodríguez Almodóvar 1989) similar a la estructura del relato folklórico.

\section{Consideraciones finales}

27 Esta aproximación a las transformaciones de una matriz folklórica desde una perspectiva genética está basada en la analogía entre las variantes de manuscritos y la vida en variantes de la tradición oral. La comparación de recorridos de «El gigante forzudo" revela la presencia de un patrón narrativo común a las distintas versiones, con variantes en contextos rurales y urbanos y en canales orales y escritos. La matriz está sometida a un mecanismo sustitutivo de detalles, en un sistema de recorridos alternativos similares a los de un hipertexto virtual. Esto puede advertirse en la comparación del relato oral riojano con la versión escrita de la leyenda del Golem. Esta versión tiene como estrategia retórica dominante, además de la hipérbole común con la versión riojana, la presentación del protagonista como emblema de protección del colectivo migrante judío frente a los peligros del ámbito urbano. La misma matriz está presente en «El Golem» de Borges, quien introduce la oralidad folklórica, en un contrapunto con el discurso literario.

La matriz de «El gigante forzudo ", en el cuento riojano, se caracteriza por la inclusión de referencias al contexto en un universo fictivo. En la leyenda urbana, la tensión entre ficción y realidad da pie para un discurso argumentativo, que recurre a citas de autoridad $\mathrm{y}$ otras estrategias de persuasión. Tal verosimilitud está mitigada por un distanciamiento del narrador, que ubica el relato en una zona fronteriza entre ficción y realidad. La versión oral y la leyenda urbana constituyen enunciados folklóricos que recrean aspectos identitarios de grupos sociales diferentes. La construcción del discurso es objeto de consideraciones metacomunicativas tanto en la narradora oral como en la leyenda escrita $\mathrm{y}$, sobre todo, en Borges, quien recurre a la matriz como pretexto para reflexionar sobre la creación estética.

La génesis de la narración folklórica, tanto en versiones orales como en fijaciones escriturales, tiene como base un mecanismo de correcciones, variantes e itinerarios alternativos semejantes a los de un hipertexto virtual. Tales itinerarios trazan caminos laberínticos, similares a « senderos que se bifurcan ». Anita guió mis primeras incursiones por estos senderos, para repensar la creación literaria desde la perspectiva de los estudios folklóricos. Me enseñó a tener el oído atento, a aprender de los más jóvenes, representados aquí por la narradora riojana, y me transmitió coraje para cruzar límites entre disciplinas, que es una clave de los estudios genéticos. 


\section{BIBLIOGRAFÍA}

Aarne, Antti and Stith Thompson. The types of the folktale : a classification and bibliography. Helsinki : Academia Scientiarum Fennica, 1928.

Assman, Jan. La memoria culturale. Scrittura, ricordo e identità politica nelle grandi civiltà antiche. Torino : Einaudi, 1997.

Bajtín, Mijail. Estética de la creación verbal. México : Siglo Veintiuno, 1982.

Barrantes, Guillermo y Víctor Coviello. Buenos Aires es leyenda. Mitos urbanos de una ciudad misteriosa. Buenos Aires : Planeta, 2004.

Barrenechea, Ana María y Julio Cortázar. Cuaderno de bitácora de "Rayuela". Buenos Aires :

Sudamericana, 1983.

Barrenechea, Ana María. La expresión de la irrealidad en la obra de Borges. Buenos Aires : Centro Editor de América Latina, 1984.

Barthes, Roland. Investigaciones retóricas I. La antigua retórica. Buenos Aires : Tiempo Contemporáneo, 1974.

Barthes, Roland et al. Análisis estructural del relato. Buenos Aires : Tiempo Contemporáneo, 1974. Borges, Jorge Luis. Obras completas. Buenos Aires : Emecé.

Bauman, Richard. "Actuación mediacional, tradicionalización, y la 'autoría' del discurso." Patrimonio cultural y comunicación. Nuevos enfoques y estrategias. Buenos Aires : Imprenta de la Ciudad, 2000, pp. 31-51.

Chertudi, Susana. El cuento folklórico. Buenos Aires : OMEP, 1978.

Cowes, Hugo. “Asunción y superación de la estilística en el pensamiento de Amado Alonso. Poesía y antología." Cauce : revista de filología y su didáctica, 18-19, 1996 (255-269).

Dégh, Linda and Andrew Vázsonyi. “Legend and belief”. En : Dan Ben-Amos (Ed.). Folklore Genres. Austin : University of Texas Press, 1976, pp. 93-123.

Derrida, Jacques. Marges de la philosophie. Paris, Les Editions de Minuit, 1985.

Ferrer, Daniel. "La critique génétique du XXIème siècle sera transdisciplinaire, transartistique et transémiotique ou ne sera pas." Cuaderno de Resumos. Fronteiras da criação. VI Encontro Internacional de Pesquisadores do Manuscrito, 1999.

Greimas, Algirdas. Semántica estructural. Madrid : Gredos, 1976.

Grésillon, Almuth. Eléments de critique génétique. Paris : Presses Universitaires de France, 1994.

Hobsbawm, Eric and Terence Ranger. The invention of tradition. Cambridge : Cambridge University Press, 1983.

Le Galliot, Jean. Psicoanálisis y lenguajes literarios. Teoría y práctica. Buenos Aires : Hachette, 1981. Le Goff, Jacques. "Las mentalidades. Una historia ambigua". Hacer la historia. Barcelona : Laia, 1984, pp. 81-98. 
Lebrave, Jean Louis. "Déchiffrer, transcrire, éditer la genèse." Proust à la lettre. Les intermittences de l'écriture. Charente : Du Lérot, 1990, pp. 141-162.

Menéndez Pidal, Ramón. “Estudios sobre el Romancero.” Obras Completas XI. Madrid, 1974.

Menéndez Pidal, Ramón. Poesía juglaresca y juglares. Madrid : Espasa-Calpe, 1975.

Mukarovsky, Jan. "Detail as the Basic Semantic Unit in Folk Art.” En : John Burbank and Peter Steiner (Ed. and trans.). The Word and Verbal Art : Selected Essays. New Haven : Yale University Press, 1977, pp. 180-204.

Nelson, Theodor Holm. Literary Machines 90.1. Padova : Muzzio Editore, 1992.

Olrik, Axel. Principles for Oral Narrative Research. Bloomington : Indiana University Press.

Palleiro, María. "La dinámica de la variación en el relato oral tradicional riojano. Procedimientos discursivos de construcción referencial de la narrativa folklórica. Síntesis de los planteos principales de la Tesis de Doctorado". Sociocriticism IX, 2, No. 18, 1993 (177-182).

Palleiro, María. Fue una historia real. Itinerarios de un archivo. Buenos Aires : Ediciones del Instituto de Filología y Literaturas Hispánicas “Dr. Amado Alonso” de la Universidad de Buenos Aires, 2004.

Palleiro, María (comp.). Yo creo ¿vos sabés ? Retóricas del creer en los discursos sociales. Buenos Aires : Ediciones de la Facultad de Filosofía y Letras de la Universidad de Buenos Aires, 2008.

Palleiro, María et al. Formas del discurso. Buenos Aires : Miño y Dávila, 2008.

Palleiro, María. “'Los tres deseos' : Cuentos maravillosos de la provincia de La Rioja, República Argentina." Archivos de Narrativa Tradicional Argentina (ANATRA). Ed. María Palleiro. CD ROM adjunto. Buenos Aires : Instituto de Filología y Literaturas Hispánicas “Dr. Amado Alonso" de la Universidad de Buenos Aires, 2011.

Propp, Vladimir. Morfología del cuento. Buenos Aires : Juan Goyanarte editor, 1972.

Reisz de Rivarola, Susana. “Ficcionalidad, referencia, tipos de ficción literaria." Lexis III, № 2, 1979 (99-169).

Rodríguez Almodóvar. Los cuentos populares o la tentativa de un texto infinito. Murcia : Secretariado de Publicaciones de la Universidad de Murcia, 1989.

Santa Biblia. Versión de Casiodoro de Reyna, revisada por Cipriano de Valera. London and New York : Sociedad Bíblica Americana.

Thompson, Stith. Motif-Index of Folk-literature. 6 vols. Copenhagen and Bloomington : Indiana University Press, 1955-1958.

Thompson, Stith. The folktale. New York : The Dryden Press, 1946.

Todorov, Tzvetan. Introducción a la literatura fantástica. Barcelona : Ediciones Buenos Aires, 1982.

Uther, Hans. The types of International Folktales : a classification and bibliography, based on the system of Antti Aarne and Stith Thompson. Helsinki : Academia Scientiarum Fennica, 2004.

\section{NOTAS}

1. En el Índice de Aarne \& Thompson (1928) cada tipo tiene una descripción temática y un número clasificatorio. Este Índice fue revisado en la actualidad por Uther, por lo cual cada tipo está identificado por un número tipológico precedido por la sigla "ATU". 
2. Estas seis categorías son: Sujeto, Objeto de Deseo, Destinador, Destinatario, Adyuvante y Oponente (Greimas 1976).

3. Las versiones de esta matriz registradas en la provincia argentina de La Rioja fueron publicados en Palleiro (2011), donde analizo sus itinerarios de dispersión.

4. La descripción temática del tipo ATU 650A, «Strong John », es: «1) The strong youth: the strong youth is the son of a woman of the woods. He sucks his mother for many years and practices his strength by uprooting trees. 2) His setting-forth: on account of his enormous appetite, he is sent from home. He sets forth on adventures. 3) The labour contract: he makes a contract to work for a man. 4) The labours: the man (or king) assigns him some tasks, in order to get rid of him ».

5. En un trabajo anterior (Palleiro 2008) efectué un análisis de esta versión, del que retomo algunos aspectos. Pueden identificarse en ella las funciones de salida del héroe (f), puesta a prueba (D), imposición y cumplimiento de una tarea difícil (T y C), victoria (V) y casamiento $(\mathrm{N})$, del inventario de Propp.

6. La metáfora combina diversas significaciones en un mismo significante (Le Galliot 1981).

7. Para una reflexión sobre los procesos constructivos de los mundos posibles, concebibles, compatibles y accesibles desde el universo real, véase Palleiro et al. (2008). Para la construcción discursiva de la creencia en el discurso folklórico, véanse Palleiro (1993) y Palleiro (comp.) (2008).

\section{RESÚMENES}

Presento aquí una propuesta de aproximación a la narrativa oral desde una perspectiva genética, que vincula las versiones y variantes del relato folklórico con las variantes textuales estudiadas por la crítica genética. Sus lineamientos conjugan estos aportes con los de la teoría informática del hipertexto. Para ejemplificar esta propuesta, analizo algunas manifestaciones de la matriz folklórica "El gigante forzudo", que identifiqué mediante la confrontación intertextual de versiones en contextos diferentes. Tomo como punto de partida la versión de la narradora Andrea Cerda ("Juan Catorce"), recogida en una investigación de campo en la provincia argentina de La Rioja. Examino luego un recorrido alternativo en una versión escrita de la leyenda del Golem ambientada en Buenos Aires, y me ocupo por último de su recreación literaria en la obra de Borges ("El Golem"). Esta aproximación apunta a poner de manifiesto los itinerarios dispersivos del relato folklórico, en una dinámica entre tradición oral y cultura letrada.

L'article présente une proposition d'approche de la narration orale à partir d'une méthode génétique qui met en relation les versions et variantes du récit folklorique avec les variantes textuelles qu'étudie la critique génétique de l'écrit. En outre, ces apports sont combinés avec ceux de la théorie informatique de l'hypertexte. Afin d'illustrer sa proposition l'auteure analyse des occurrences de la matrice folklorique «El gigante forzudo» («Strong John» [ATU 650 A]), qu'elle a identifiée à partir de la comparaison intertextuelle de versions dans des contextes différents. Le point de départ est la version de la narratrice Andrea Cerda ("Juan Catorce"), recueillie lors d'une recherche de terrain dans la province argentine de La Rioja. Par la suite est examiné un exemple alternatif dans une version écrite de la légende du Golem transposée à Buenos Aires, et enfin la récréation littéraire de la matrice folklorique dans l'œuvre de Borges (poème «El Golem»). Cette étude s'attache à montrer la dispersion des itinéraires du récit folklorique à l'intérieur de la dynamique tradition orale- culture lettrée. 
In this article, I propose an approach to oral narrative from a genetic perspective, linking the versions and variants of folktale with textual variants studied by genetic criticism. The theoretical guidelines combine genetic concepts such as "textual genesis" with those of hypertext theory. In order to explain such proposal, I analyse alternative itineraries of the folk narrative matrix "Strong John" (ATU 650 A), by means of an intertextual comparison of different versions both in rural and urban contexts. As a point of departure, I analyse the version "Juan Catorce" by Andrea Cerda, collected in the Argentine province of La Rioja. Then I examine an alternative itinerary in an urban written version of the legend of the Golem set in Buenos Aires. At last, I consider a literary recreation in the poem "El Golem" by Jorge Luis Borges. The aim of this approach is to highlight the dispersive itineraries of folk narrative matrices, and the dynamics between oral and written culture.

\section{ÍNDICE}

Mots-clés: critique génétique, conte folklorique, itinéraires hypertextuels, Golem, tradition argentine

Keywords: genetic criticism, folk narrative, hypertexts, Golem, Argentine tradition

Palabras claves: genética textual, narrativa folklórica, hipertexto, Golem, tradición argentina

\section{AUTOR}

\section{MARÍA INÉS PALLEIRO}

Instituto de Filología y Literaturas Hispánicas “Dr. Amado Alonso”. Universidad de Buenos Aires inespalleiro@gmail.com

Consejo Nacional de Investigaciones Científicas y Técnicas (CONICET) 